\title{
Vías moleculares patogénicas del linfoma T/NK extranodal de tipo nasal asociadas con virus de Epstein Barr: Revisión narrativa
}

\author{
Molecular pathways related to Epstein Barr virus in extranodal NK/T cell lymphoma, \\ nasal type: Narrative review \\ Fabiola Valvert (DiD 1,2*, Armando Cáceres (D) 3,4 \\ ${ }^{1}$ Liga Nacional contra el Cáncer e Instituto de Cancerología, Guatemala, ${ }^{2}$ Doctorado en Ciencias Biomédicas, \\ Escuela de Estudios de Postgrado, Facultad de Ciencias Médicas, Universida de San Carlos de Guatemala; \\ ${ }^{3}$ Laboratorio de Investigación de Productos Naturales (Lipronat), Facultad de Ciencias Químicas y Farmacia, \\ Universidad de San Carlos de Guatemala, ${ }^{4}$ Laboratorios de Productos Naturales Farmaya, Guatemala \\ *Autor al que se dirige la correspondencia: cfvalvert@gmail.com
}

Recibido: 29 de junio 2020 / Revisión: 12 de junio 2021 / Aceptado: 16 de noviembre 2021

Resumen

$\mathrm{E}$ 1 virus de Epstein Barr (VEB) se encuentra presente en el 100\% de los casos de linfoma T/NK extranodal de tipo nasal (ENKTL) y juega un papel importante en la etiopatogenia de esta enfermedad. El objetivo de esta revisión es actualizar el conocimiento de las vías moleculares genéticas y epigenéticas utilizadas por el VEB en la oncogenesis del ENKTL. Para ello se realizó una revisión de la literatura, en las bases de datos de PubMed y Google Scholar, sobre los mecanismos que utilizan las proteínas virales como la proteína de membrana latente (LMP1) y el antígeno nuclear Epstein Barr 1 (EBNA1) para activar proteínas antiapoptóticas del huésped y proteínas relacionadas a proliferación celular, a través de las vías moleculares JAK/STAT (Janus quinasas/señales de transducción y activación de proteínas de transcripción), NF- $\kappa$ B (el factor nuclear potenciador de las cadenas ligeras kappa de las células B activadas) EZHZ2 (Enhancer of Zeste 2 Polycomb repressive Complex 2) y PI3K/ Akt (Fosfoinositido 3 quinasa/proteína quinasa B); también se revisó el papel de las proteínas virales BNLF2a, BILF y BDLF3 en la evasión inmune del virus. También LMP1 aumenta la expresión de PDL-1 (ligando de la muerte celular programada), contribuyendo a la disminución de la respuesta inmunológica. A nivel epigenético se abordan los cambios del perfil de metilación en las áreas promotoras de genes supresores de tumor y se explica la función de los miARN de VEB que participan inhibiendo genes supresores de tumor o activando genes que aumentan la proliferación.

Keywords: Síndrome linfoproliferativo, herpesvirus, oncogénesis, evasión inmune, epigenética

\section{Abstract}

$\mathrm{E}$ pstein Barr virus (EBV) is present in 100\% of cases of nasal-type extranodal NK/T cell lymphoma (ENKTL). - It plays an important role in the etiopathogenesis of this disease. The objective of this review is to update the knowledge of the genetic and epigenetic molecular pathways used by EBV in the oncogenesis of ENKTL. To this end, a literature review was carried out in the PubMed and Google Scholar databases on the mechanisms used by viral proteins such as latent membrane protein (LMP1) and Epstein Barr 1 nuclear antigen (EBNA1) to activate host antiapoptotic proteins avoiding cell death and activating cell proliferation, through the molecular pathways JAK/STAT (Janus kinases/signal transduction and activation of transcription proteins), NF- $\kappa B$ (the nuclear factor enhancing the kappa light chains of activated B cells) EZHZ2 pathways (Enhancer of Zeste 2 Polycomb repressive Complex 2) and PI3K/Akt (Phosphoinositide 3 kinase protein kinase B). The role of the viral proteins: BNLF2a, BILF and BDLF3 in the virus immune evasion. It is currently recognized that LMP1 increases the expression of PDL-1 (programmed cell death ligand), contributing to the decrease in the immune response. Thus, the epigenetic changes in the methylation profile in the promoter areas of tumor suppressor genes, was also reviewed. Finally role of EBV miRNAs participate in inhibiting tumor suppressor genes or activating genes that increase proliferation.

Palabras claves: Lymphoproliferative syndrome, herpesvirus, oncogenesis, immune evasion, epigenetic 


\section{Introducción}

El virus de Epstein Barr (VEB) es un Gammaherpesvirus tipo 4 (Stanfield \& Luftig, 2017). El $90 \%$ de la población mundial está infectada de forma latente del VEB. El virus se ha detectado en todas las poblaciones y todas las áreas geográficas del mundo, pero con notable variación en el genoma según la localización geográfica (Hialgrim et al., 2007; Palser et al., 2015; Rickinson et al., 2007). La alta prevalencia de VEB esta dada porque el virus puede permanecer durante toda la vida dentro del huésped en estadio latente (no replicativo), para poder evadir al sistema inmunológico.

El virus utiliza la maquinaria proliferativa de la célula para sintetizar sus propias proteínas y en situaciones de estrés celular o inmunosupresión adquiere ventajas para sintetizar más proteínas y aumenta su replicación y también la replicación de la célula huésped (linfocito B), sin ser reconocido por el sistema inmunológico (Lambris., 2008; Rowe\& Zuo, 2010).

El VEB fue el primer virus identificado como oncogénico y según su variedad genómica se relaciona con diferentes tipos de cáncer, entre los que se incluye el linfoma T/NK extranodal de tipo nasal (Tsai et al., 2017). El ENKTL es un linfoma altamente agresivo que destruye la región nasal y el paladar. Este tipo de linfoma tiene una alta incidencia en Guatemala con respecto a Estados Unidos y Europa (Laurini et al., 2012; Sánchez-Romero et al., 2019; Valvert et al., 2021) aunque debido a la constante inmigración asiática y de latinoamericanos a Estados Unidos la incidencia en esta región es cada vez más alta (Cohen et al., 2020; Haverkos et al., 2016; Sánchez-Romero et al., 2021).

Durante el estadio de latencia II del VEB se desarrolla el Linfoma T/NK. El virus invade los linfocitos T (LT) citotóxicos y las células Natural Killer (NK) y dentro de estas células el VEB sintetiza EBNA 1, LMP1 y proteínas líticas como BHRF1, BNLF2a, BDLF3, BILF1 y BGLF5, dichas proteínas interactúan con proteínas y cascadas de señalización del huésped para evadir al sistema inmunológico y a través de la activación de JAK/STAT y el factor nuclear (NF) kB del huésped aumentan la proliferación de las células NK y promueven el desarrollo del ENKTL (Horst et al., 2012; Huang et al., 2010; Koo et al., 2012; Ng et al., 2011; Pudney et al., 2005; Rowe \& Zuo, 2010; Tse et al., 2013).

En los últimos 5 años se han reportado nuevas vías moleculares relacionadas a virus de VEB y
ENKTL, es por ello que en esta revisión resumiremos los artículos publicados en las bases PubMed y Google Scholar entre los años 2016 al 2021 buscando las palabras Epstein Barr virus, Molecular pathways y $N K / T$ cell lymphoma.

\section{Contenido}

\section{Linfoma T/NK extranodal de tipo nasal}

Es la neoplasia linfoide de células NK más frecuente según la Organización Mundial de la Salud (Swerdlow et al., 2016). Es una neoplasia frecuente en algunas regiones de Asia y Latinoamérica por lo que se plantea que uno de los factores de riesgo de este tipo de linfoma es la etnicidad (Kanno et al., 2000; Li et al., 2016). En Guatemala representa el $9 \%$ de los linfomas (Valvert et al., 2021), en México se reportó un 40\% de todos los linfomas T (Avilés, 2015), muy superior a la incidencia en caucásicos que es $<.05 \%$ (Laurini et al., 2012), probablemente asociado a su descendencia maya (Sánchez-Romero et al., 2019).

El ENKTL es una enfermedad altamente mortal, con una supervivencia entre el $10-40 \%$ en estadios diseminados (Yang et al., 2021) en contraste con los estadios tempranos en los que se ha reportado un buen pronóstico (Hong et al., 2019; Lehrich et al., 2021). El tumor suele iniciar en la región nasal, infiltrando frecuentemente el paladar, senos paranasales, amígdala y anillo de Waldeyer. También puede diseminarse a otros sitios como piel, pulmón y tracto gastrointestinal (de Arruda et al., 2021; Sánchez-Romero et al., 2019; Swerdlow et al., 2016).

El diagnóstico se hace en la biopsia del tumor, la cual presenta áreas de tejido extensamente necrótico, ulcerado, con un patrón angiocéntrico y angioinvasivo. El estudio confirmatorio se hace a través de la inmunohistoquímica que se caracteriza por la expresión de CD3 citoplasmático, CD 56, granzima y perforina y la confirmación de la presencia de VEB por medio del estudio de hibridación in situ para Epstein-Barr virus-encoded small RNAs (EBER) (Campo et al., 2011; Hue et al., 2020; Sánchez-Romero et al., 2019).

El ENKTL se encuentra fuertemente relacionada al VEB, el cual está presente en todos los casos (de Arruda et al., 2021). A diferencia de otros tipos de linfoma $\mathrm{T}$ y $\mathrm{B}$ asociados a VEB como el linfoma $\mathrm{T}$ periférico, linfoma de Hodgkin, linfoma de Burkitt y linfoma difuso de células grandes B en el que se aísla el 
virus solo en un porcentaje de los pacientes (Swerdlow et al., 2016).

El VEB dentro de la célula NK interfiere en el funcionamiento de la célula, promoviendo la proliferación y evadiendo la apoptosis. A ello se suma la inestabilidad genética producida por el virus que da lugar a múltiples alteraciones genéticas en la célula que darán como resultado la transformación a una célula tumoral.

\section{Herpesvirus}

La familia Herpesviridae infecta a una variedad de células de vertebrados. Se trata de infecciones endémicas que pueden cursar paucisintomáticas o causar enfermedades como la mononucleosis infecciosa producida por el VEB, la enfermedad por Citomegalovirus, el Herpes tipo 1 y 2, Varicela y Herpes Zoster producidos por el virus de la Varicela Zoster y el Sarcoma de Kaposi producido por el Virus del Herpes tipo 8 (Louten et al., 2016).

Los herpesvirus tienen una estructura que le confiere características que le permite sobrevivir dentro del huésped. Se compone de un núcleo con una doble cadena de ADN; rodeando al núcleo una cápside icosaédrica construida con 162 capsómeros que protegen el material genético del virus. Entre la cápside y la envoltura se encuentra el tegumento que contiene las enzimas virales necesarias para la replicación viral y la defensa contra el huésped. La envoltura es la capa más externa, que contiene abundantes glicoproteínas que se une a la célula del huésped y facilitan su entrada. Después de la fusión de la envoltura viral, la nucleocápside se libera en el citoplasma y las proteínas del tegumento facilitan su transporte a lo largo de los microtúbulos hacia la envoltura nuclear. Ya dentro del núcleo el material genético viral se mantiene en forma episomal y utiliza la ARN polimerasa del huésped para replicar sus proteínas (Louten et al., 2016).

Durante la primoinfección los LT citotóxicos y las células NK son los encargados de eliminar el virus y controlar la replicación viral, hasta que el virus queda en estado de latencia dentro del núcleo de diferentes tipos celulares replicando el mínimo de proteínas y microARN para no ser reconocidos por el huésped. Estos períodos se van alternando con reactivaciones en donde el virus pasa a un estadio lítico, período de una rápida replicación del virus. La reactivación del virus puede suceder como respuesta a diferentes estímulos celulares, como la luz ultravioleta, fiebre, infecciones bacterianas, estados inflamatorios crónicos e inmuno- supresión del huésped y provocar enfermedad (Coşkun et al., 2017; Goade et al., 2001; Mansfield et al., 2016; Walton et al., 2014).

Durante la fase lítica, o de producción de viriones, muchas de las células son lisadas por las células NK o LT citotóxicos y el virión logra salir de la célula e infecta nuevas células fusionando su membrana a la nueva célula o por endocitosis (Louten et al., 2016).

Los herpesvirus afectan la respuesta antiviral del huésped, interfiriendo con la señalización de citoquinas y quimiocinas (Alcami, 2003), alterando la cascada del complemento (Lambris et al., 2008), previniendo el reconocimiento y eliminación de células infectadas por células NK (Lanier et al., 2008) e inhibiendo la señalización inmune innata por receptores de reconocimiento de patrones (PRRs), tales como los receptores Toll-like y receptores similares a Retinoic acidinducible gene 1 (RIGI) (Bowie \& Unterholzner, 2008). Los herpesvirus utilizan diversas estrategias para manipular la respuesta inmune adaptativa del huésped, esto incluye el uso de receptores Fc codificados por herpesvirus para inhibir los mecanismos efectores mediados por anticuerpos y subvertir el complejo mayor de histocompatibilidad (MHC) clase II y, particularmente, las vías de procesamiento y presentación del antígeno MHC clase I (Griffin et al., 2010; Hansen \& Bouvier, 2009; Lubinski et al., 1998; Wiertz et al., 2007).

\section{Virus de Epstein Barr}

De la familia de los gammaherpesvirus su ADN contiene 85 genes y está rodeado por una nucleocápside, un tegumento proteínico y una capa externa de envoltura lipídica.

El VEB se transmite a través de la saliva en la mayoría de los casos, pero también se puede transmitir por la sangre, semen u órganos trasplantados.

Una vez en las vías respiratorias superiores el virus se introduce en las células epiteliales por fusión directa entre la envoltura viral y la membrana plasmática de la célula; posteriormente en los linfocitos B (LB) lo hace a través de la unión de la glicoproteína viral gp350/220 con el receptor celular CD21. El virus puede permanecer durante toda la vida del individuo en estadio latente, y reactivarse en pocas ocasiones y por breves períodos de tiempo (Crombie \& LaCasce, 2019).

El VEB en estadio de latencia limita la expresión génica a nueve proteínas virales, EBNA1, EBNA2, EBNA3A, EBNA3B, EBNA3C, BamHI A (BART), 
EBER1, EBER2 y proteína líder (PL), esta última controla la expresión de tres proteínas latentes de membrana (LMP1, 2a y 2b) (Merlo et al., 2010; Petrara et al., 2013; Rowe \& Zuo, 2010).

Existen tres tipos de latencia, que van a depender de los genes expresados en la célula huésped. En el estadio de latencia I la expresión del genoma viral queda limitada a la expresión de EBERs y a la proteína EBNA1, lo cual le permitirá escapar de los LT citotóxicos y favorecer la persistencia de la infección latente. Este patrón de latencia se asocia a linfoma Burkitt. Latencia II se caracteriza por la expresión de EBNA1, LMP1, LMP2A y 2B y los EBERs. A este patrón se asocia el linfoma T/NK extranodal y el linfoma de Hodgkin, y el estadio de latencia III se observa en la mayoría de los trastornos linfoproliferativos B asociada a inmunodeficiencia. La inmunosupresión hará que se expresen las nueve proteínas anteriormente mencionadas sin que sean reconocidas por los linfocitos $\mathrm{T}$ (Tse et al., 2013).

Cuando los mecanismos de inmunidad celular se encuentran alterados, el virus se replica con mayor libertad, expresando antígenos en la membrana celular que interactúan con diferentes proteínas y cascadas de señalización que van a contribuir a la replicación del virus, pero así también aumentan la predisposición a la transformación oncogénica (Crombie \& LaCasce, 2019).

Se ha demostrado que en estados de inmunosupresión relacionados a la edad, medicamentos inmunosupresores y condiciones genéticas hereditarias se facilita la replicación del virus dentro de los LB, produciendo un cambio blastoide en el linfocito e hiperplasia linfocítica. En estas condiciones el virus puede evadir al sistema inmunológico, manipular el ciclo celular y el proceso de muerte celular y promover la supervivencia del tumor (Hui et al., 2019).

\section{VEB y evasión inmunológica}

El VEB toma la célula B de memoria para sobrevivir en estado de latencia y utiliza su maquinaria genética como una fábrica productora de virus y es capaz de adaptarse a las medidas antivirales tomadas por el huésped especialmente por los LT citotóxicos. El VEB logra mantener un equilibrio entre la replicación viral y la respuesta inmune innata y adaptativa (Ressing et al., 2015). Durante la replicación viral lítica se pueden expresar 80 proteínas. Inicialmente se expresan proteínas tempranas, Zta y Rta, sintetizadas por los genes BZLF1 y BRFL1 (Bhaduri-McIntosh., 2007).
Zta y Rta son factores de transcripción que activarán la cascada de transcripción genética viral. Inmediatamente el sistema inmunológico desencadenará una respuesta inmune humoral y celular que eliminará las células infectadas (Griffin et al., 2010). Sin embargo, la síntesis de diferentes variantes genéticas de las proteínas líticas, por diversos mecanismos, asegurara que el virus pueda esconderse de los LT citotóxicos y asegurar la inmortalidad de la célula huésped (Horst et al., 2012; Rowe \& Zuo, 2010).

El papel fundamental de los LT citotóxicos es eliminar las células infectadas por el virus, a través de la detección de los péptidos virales presentados al linfocito por el MHC clase I durante la presentación de antígeno. Estos péptidos son producto de la degradación proteosómica de las proteínas virales en el citosol. Estos péptidos son transportados al retículo endoplásmico a través del transportador asociado con el procesamiento de antígeno (TAP) y posteriormente se cargan en moléculas de HLA I (Hislop et al., 2007).

Los mecanismos de evasión del reconocimiento del LT citotóxico se producen por inhibición de TAP, por medio de la proteína BNLF2a del VEB que interfiere con la unión de ATP y péptido al transportador de TAP. Por lo que se reduce la expresión de los complejos HLA I/Péptido (Hislop et al., 2007; Horst et al., 2009). La proteína BILF1 del VEB hace que las moléculas de MHC de clase I y MICB que se encuentran en la superficie, se dirijan hacia los lisosomas y sean degradados (Zuo et al., 2009). BDLF3 es otra proteína que disminuye la expresión de moléculas del MHC clase I y II, internalizándolas y enlenteciendo su aparición en la superficie (Quinn et al., 2016).

La proteína viral EBNA1 también puede interferir con la presentación del antígeno, afectando el procesamiento de péptidos, interfiriendo con la degradación proteasomal del polipéptido EBNA1, a través de su gran región repetitiva que codifica un dominio de repetición Gly-Ala. EBNA1 también desempeña un papel clave en el mantenimiento del VEB en las células infectadas, limitando la expresión de los antígenos virales y facilitando la replicación episomal (Rowe \& Zuo, 2010).

En algunas situaciones el virus puede producir homólogos virales de citoquinas humanas como IL-10, los cuales le facilitarán evadir al sistema inmunitario (Merlo et al., 2010). La proteína viral IL-10 sintetizada por el gen BRCF1 permite al virus escapar del reconocimiento de LT regulando negativamente la expresión en la superficie celular de HLA I a través de la inhi- 
bición transcripcional de la expresión de TAP1. Esta citocina comparte funciones con la IL-10 humana por lo que sus efectos sobre el sistema inmune son múltiples (Horst et al., 2012). Por otra parte la baja expresión de HLA específicamente HLA-A se presenta hasta en un $16 \%$ de los casos y ha sido reportado como de mal pronóstico (Polprasert et al., 2021).

BNLF2a al igual que otras proteínas virales líticas tardías (BGLF5, BILF1) puede interferir en la unión huésped-patógeno y la respuesta inmunológica del huésped será menos agresiva contra estas proteínas, que con las proteínas líticas de expresión temprana (Pudney et al., 2005).

La oncoproteína viral LMP1 desregula al transductor de señal y activador de la transcripción 3 (STAT 3) quien tiene una importante participación en la vigilancia y evasión inmune. STAT3 estimula la expresión del ligando de la muerte programada (PDL-1) y de la proteína de muerte celular (PD-1), provocando tolerancia inmunológica y de esta manera supervivencia de la célula (Song et al., 2018). Se demostró la correlación directa entre la expresión de STAT3 y el aumento en los niveles de PDL-1, así también se demostró que aumenta la producción de la proteína 4 asociada a linfocitos citotóxicos (CTL-4) la cual está encargada de regular la respuesta inmune, demostrando su importancia en el control inmunitario (Han et al., 2014; Huynh et al., 2019; Jo et al., 2017; Kim et al., 2016). El análisis mutacional de ENKLT en Latinoamérica mostro que las mutaciones en STAT3 eran las más frecuentes (Montes-Mojarro et al., 2020)

Por otra parte, se ha sugerido que el genoma del VEB es diferente en los pacientes con ENKTL y en otros tipos de cáncer, con respecto a los individuos sin cáncer. También se ha reportado que el VEB en pacientes con ENKTL tiene capacidad de introducir fragmentos de ADN en el genoma del huésped. Todo ello orienta hacia un papel en las propiedades de evasión inmune y la patogénesis de la enfermedad (Peng et al., 2019).

\section{Mecanismos moleculares de VEB y su potencial oncogénico}

El VEB fue el primero y uno de los más importantes virus asociado a cáncer, entre los que se incluye el linfoma. Fue descubierto por el científico inglés Dennis Burkitt en 1958 e identificado por Anthony Epstein e Yvonne Barr en 1964 (Farrell, 2019).

El VEB a través de oncoproteínas y la expresión de mARNs tienen la capacidad de generar cambios genéticos y epigenéticos en la célula del huésped que desencadenan el tumor. El estímulo constante de las oncoproteínas virales de VEB sobre la célula es el detonante fundamental del cáncer, el cual se desarrollará a través de cuatro mecanismos: un aumento en la proliferación celular, inhibición de la apoptosis, inhibición de genes supresores de tumor, y aumento en la angiogénesis (Tabla 1).

También la predisposición del huésped a este tipo de linfoma es fundamental y fue reportado en relación a la baja frecuencia del HLA-A*0201 en pacientes con ENKTL de Japón. La cual podría dificultar en estos individuos la capacidad para suprimir el desarrollo del tumor (Kanno et al., 2000). Mas recientemente en China se asoció un SNP común (rs9277378) en el alelo HLA-DPB1 específicamente el haplotipo Gly84Gly85-Pro86-Met87 el cual confiere un riesgo 2.3 veces mayor de ENKTL en comparación con los grupos de pacientes sin esta enfermedad. La presencia de este haplotipo podría explicar un problema en la presentación de antígenos, contribuyendo a la susceptibilidad hereditaria (Li et al., 2016).

Dentro de los mecanismos moleculares de VEB se destaca la activación constante de JAK/STAT por la proteína viral LMP1 la cual juega un papel primordial en la proliferación celular en el ENKTL (Koo et al., 2012). Las mutaciones en JAK/STAT permite la sobrexpresión de MYC y este promueve la sobrexpresión de factores transcripcionales. Se cree que estos factores transcripcionales activan al EZH2 un componente del complejo represivo policomb 2 que también se ha demostrado que esta desregulado en ENKTL (De Mel et al., 2019). La expresión positiva de EZH2 en líneas celulares de ENKTL confiere ventajas de crecimiento al tumor (Yan et al., 2013). Existen otros genes que promueven la proliferación del ciclo celular y están sobrexpresados en ENKTL como 1q (CDCA1, NEK2), 2q (E2F6), 7q (RHEB), 17q (CDC27) y $20 p$ (DSTN). También se han encontrado otros genes que pueden impulsar la proliferación y están regulados positivamente en las líneas celulares de ENKTL como la quinasa 2 dependiente de ciclina (CDK2) un regulador de la progresión del ciclo celular, y HSPCA (choque térmico de la proteína 1-alfa de $90 \mathrm{kDa}$ ) (De Mel et al., 2019). Se ha reportado que la desregulación de ARN mensajero afecta las vías pro-proliferativas como AKT y MAPK, esta última aumenta la expresión de PDL-1 (Lv et al., 2020). Específicamente, miR-21 y miR-155 están sobre expresados en ENKTL, lo que re- 
Tabla 1

Alteraciones moleculares promovidas por VEB y sus implicaciones celulares

\begin{tabular}{ll}
\hline Alteraciones genéticas & \multicolumn{1}{c}{ Alteraciones epigenéticas } \\
\hline Aumentan la proliferación & \\
Aumento en la expresión: & Silenciamiento epigenético: \\
-MYC & MiRNA-26, MiRNA-101, MiRNA-Bart-20 \\
-JAK/STAT & MiRNA-Bart-16, MiRNA-Bart-8, MiRNA-Bart-15 \\
-RUNX3 & \\
-EZH2 & \\
Función Antiapoptótica & \\
Aumento en la expresión: & \\
-NFKB & \\
-Survivina & BHRF1, BKRF3, MiRNA-Bart-9, \\
-PI3K/Akt & \\
-PDL-1 & \\
Bloqueo de genes supresores de tumor & \\
Disminución en la expresión: & \\
-STAT 3 & \\
-PTPRK & DOK1, PTPRK, STAT3, DLEC1, \\
-BLIMP1 & TET-1 y 2, CADM1, DAL1 \\
Promueven angiogénesis & \\
Aumento en la expresión: & \\
-VEGF & \\
\hline
\end{tabular}

sulta en la desregulación de la ruta de proliferación AKT (De Mel et al., 2019).

Otro mecanismo por el que VEB participa en la oncogénesis es a través de la inhibición de la muerte celular programada. La expresión de la oncoproteína LMP1 actúa mimificando un receptor constitutivamente activo de la familia del factor de necrosis tumoral 1 CD40/TNFR, regulándolo positivamente a las proteínas antiapoptóticas, con lo cual se aumenta la supervivencia de la célula (Kobayashi et al., 2008). También se ha descrito una variación de la secuencia de aminoácidos para la proteína antiapoptótica BHRF1 que confieren protección contra la apoptosis (Horst et al., 2012). El NFאB es un factor de transcripción con funciones de supervivencia y antiapoptóticas que se sabe que están sobrexpresadas en las neoplasias linfoides y en el caso de las neoplasias asociadas a VEB, activadas por LMP-1. Se demostró en dos estudios de programación de expresión genética (GEP) que NF- $\kappa \mathrm{B}$ y sus genes diana estaban sobreexpresados en ENKTL (Huang et al., 2010; Ng et al., 2011).

Probablemente la vía más importante para inducir neoplasias malignas es la de PI3K/Akt, esta vía es activada por LMP1, a través principalmente de sus dominios de señalización de cola C-terminal y, en particular, de la región activadora carboxiterminal 1 (CTAR1) que inhiben la apoptosis (Mainou et al., 2007). La alta expresión de PI3K especialmente la isoforma $\mathrm{PI} 3 \mathrm{~K} \alpha$ se ha relacionado con peor pronostico de la enfermedad y su inhibición a través de una molécula llamada copanlisib demostró que se suprimía el crecimiento de las células tumorales in vivo e in vitro (Huang et al., 2020). También la expresión de survivina estimulada por LMP1 se relacionó a inhibición de la apoptosis (Sun et al., 2015).

Las alteraciones genéticas en la región $6 \mathrm{q}$ son comunes en ENKTL, estas participan inhibiendo genes supresores de tumor, como PRDM1, FOXO3, ATG5, AIM1 y HACE1. Se ha demostrado que la inhibición del receptor tipo tirosina-proteína fosfatasa $\mathrm{k}$ (PTPRK) localizado en el cromosoma 6q puede ser provocado por VEB (Flavell et al., 2008), la baja expresión de PTPRK debido a deleciones y la hipermetilación aberrante del promotor de PTPRK se ha relacionado con la reducción de la expresión de STAT3 y la inhibición de su papel como gen supresor de tumor (Chen et al., 2015). Otras 
mutaciones en genes supresores de tumores incluyen TP53 presente en el $20-60 \%$ de los casos, y el gen CD95 (Fas) presente en el 50\%, confiriendo el primero de ellos un peor pronóstico (Gruhne et al., 2009; Huang et al., 2018). También se han reportado que la inhibición del gen NHEJ1 implicado en la reparación del ADN, puede provocar inestabilidad genética, dicho gen se inhibe por la integración de material genético viral en el genoma del huésped (Peng et al., 2019).

Otro mecanismo recientemente reportado es el de la sobrexpresión de la proteína asociada al tumor 1 de Wilms (WTAP), una de las principales ARN N6adenosina metiltransferasa, la cual promueve proliferación e inhibición de la apoptosis (Ma et al., 2021).

La linfangiogénesis promueve la diseminación de la enfermedad a través de los conductos linfáticos a los ganglios locoregionales. Recientemente se demostró que miR-155 regula la linfangiogénesis en ENKTL disminuyendo la expresión del gen 1 relacionado con brahma (BRG1) y se correlacionó con un aumento en el factor de crecimiento endotelial (VEGFC) y por ende en la angiogénesis (Chang et al., 2019).

Recientemente se encontró que las variaciones somáticas de nucleótido único (SNVs) del VEB están relacionadas con la patogénesis del ENKTL. Los SNVs se encontraron con mayor frecuencia en la proteína viral BALF3 y en casos con mayor inestabilidad genómica. Por lo que asocian a BALF3 con el daño al ADN $\mathrm{y}$ como productor de inestabilidad genómica (Xiong et al., 2020)

El linfoma T/NK extranodal presenta un conjunto de alteraciones genéticas que se definen como auténticas firmas moleculares, tales como la deleciones de $6 \mathrm{q} 22.3$ y $9 \mathrm{p} 21.3$, y las ganancias en 1q22, 2q22.2, $6 \mathrm{p} 21.3,7 \mathrm{q} 21.1,11 \mathrm{q} 24.3,13 \mathrm{q} 14.2$ y $17 \mathrm{q} 21.2$ y que no presentan pérdida de 14q11.2 (loci TCRA) como los linfomas T/NK nodales (Ng et al., 2018).

\section{Desregulación epigenética}

La identificación de rutas oncogénica que involucran la desregulación epigenética promovida por el VEB ha sido un avance muy importante. El 77\% (34/44) de los casos de ENKTL presentan alteraciones epigenéticas (Ying et al., 2007). El perfil de metilación de las islas $\mathrm{CpG}$ en todo el genoma ha mostrado un epigenotipo único de metilación en las áreas promotoras de genes supresores de tumor en cánceres asociados a VEB. Este alto grado de metilación esta dado por la producción de oncoproteínas o ARN codificado por
VEB, quienes modulan la maquinaria epigenética de la célula huésped, a través de las ADN metiltransferasas, las metiltransferasas de histonas, las proteínas del grupo policomb y las deacetilasas de histonas que produce el silenciamiento de genes supresores de tumor tales como DOK1 (Siouda et al., 2014), DLEC1 (Wang et al., 2012), PTPRK en la señalización de STAT3 (Chen et al., 2015) y TET1 y 2 (Li et al., 2016).

La molécula de adhesión-1 CADM1 y DAL1 funcionan como genes supresores de tumor. Ambas moléculas están silenciadas en el ENKTL, sugiriéndose un papel en la patogénesis de la enfermedad (Fu et al., 2009).

Se han demostrado alteraciones genéticas en BCOR un gen que codifica un regulador epigenético involucrado en el complejo represivo polycombl que participa en el silenciamiento de genes supresores de tumor en ENKTL y también se han relacionado con otros tumores asociados y no asociados a VEB. Se ha identificado que entre $12-32 \%$ de los casos de ENKTL presentan mutaciones en este gen (Dobashi et al., 2016; Lee et al., 2015).

Los marcadores miARN-Bart-20, miARNBart-16, miARN-Bart-8, miARN-9, miARNBart-15a desregulan las vías de señalización en ENKTL (Gao., 2020; Mei et al., 2019). También se ha demostrado que miARN-21 y/o miARN-155 contribuyen al desarrollo del ENKTL a través de la activación de AKT, que va a disminuir el proceso de apoptosis (Yamanaka et al., 2009).

La sobreexpresión de EZH2 mediante la supresión de sus microARN reguladores negativos miR26 y miR101 silencian la expresión de genes supresores de tumores y aumentan la proliferación (Yan et al., 2013).

\section{Terapia dirigida en ENKTL}

El descubrimiento de las vías moleculares que utiliza VEB y que desencadenan el tumor, ha permitido la investigación de nuevos fármacos diana, como lo son los inhibidores inmunológicos checkpoint entre los que se destacan los anticuerpos anti PDL-1 los cuales son muy efectivos contra ENKTL en pacientes refractarios o recaídos (De Mel et al., 2018; Kwong et al. 2017), También se han desarrollado anticuerpos IgG anti LMP1 que inhiben la proliferación e inducen apoptosis en ENKTL a través de la inhibición de la fosforilación de JAK3 y STAT3 (Mao et al., 2017), también se ha demostrado que las drogas que regulan mecanismos epigenéticos como los agentes desmeti- 
lantes e inhibidores de desacetilasa de histona tienen efectos antitumorales en ENKTL recaídos o refractarios (Du et al. 2020; Yamaguchi et al., 2018; Ying et al. 2007; Zhou et al. 2018).

\section{Conclusión}

LMP1 es la proteína viral con un papel protagonista en el desarrollo del ENKTL, promoviendo la evasión inmunológica a través de la expresión de PDL-1 y PD-1 provocando tolerancia inmunológica y el aumento de CTL-4 que reprime la respuesta de los LT citotóxicos, también promueve el aumento de la proliferación celular por la activación de factores transcripcionales que activan EZH2, la desregulación de los microARN mensajero miR-21 y miR-155 que activan vías de proliferación como AKT y MAPK. El aumento de la proteína survivina estimulado por LMP1 produce la inhibición de la apoptosis. También LMP1 participa en la inhibición de genes supresores de tumor como TP53. La hipermetilación de PTPRK que disminuye la expresión de STAT 3 altera su función como gen supresor de tumor. La inhibición de NHEJ1 evita la reparación del ADN mutado provocando inestabilidad genómica (Somasundaram et al., 2019). Otra proteína viral identificada como promotora de la evasión del sistema inmune es BDLF3. La proteína viral BALF3 se asocia con el daño del ADN y como productor de inestabilidad genómica. También existen factores hereditarios del huésped que lo predisponen al ENKTL y que podrían justificar su distribución geográfica como la presencia del SNP (rs9277378) en el alelo HLA-DPB1. En cuanto al tratamiento del ENKTL, el reconocimiento de nuevas vías moleculares ha permitido el uso en ensayos clínicos en los últimos años de nuevas drogas que no son quimioterapia, como los son los fármacos anti PDL-1 y los inhibidores de deacetilasa de histona que han demostrado eficacia en el tratamiento. El mejor entendimiento en los últimos años de los mecanismos moleculares genéticos y epigenéticos utilizados por las proteínas del VEB en el desarrollo de ENKTL, han contribuido a estructurar mejor la biología del tumor y encontrar nuevos tratamientos diana.

\section{Contribución de los autores}

Coordinación, elaboración y revisión del Documento: Todos los autores

\section{Materiales suplementarios}

No tiene materiales suplementarios

\section{Referencias}

Alcami, A. (2003). Viral mimicry of cytokines, chemokines and their receptors. Nature Reviews Immunology, 3(1), 36-50. https://doi.org/10.1039/ nri980

Avilés, A. (2015). Nasal NK/T-cell lymphoma. A comparative analysis of a Mexican population with the other populations of Latin-America. Mediterranean Journal of Hematology and Infectious Diseases 7(1):e2015052. https://doi.org/ 10.4084/mjhid.2015.052.

Bhaduri-McIntosh, S., Landry, M. L., Nikiforow, S., Rotenberg, M., El-Guindy, A., \& Miller, G. (2007). Serum IgA antibodies to EpsteinBarr virus (EBV) early lytic antigens are present in primary EBV infection. Journal of Infectious Disease, 195, 483-492. https://doi.org/ 10.1086/510916

Bowie, A. G., \& Unterholzner, L. (2008). Viral evasion and subversion of pattern-recognition receptor signaling. Nature Review Immunology, 8(12), 911-922. https://doi.org/10.1038/nri2436

Campo, E., Swerdlow, S. H., Harris, N. L., Pileri, S., Stein, H., \& Jaffe, E. S. (2011). The 2008 WHO classification of lymphoid neoplasms and beyond: evolving concepts and practical applications. Blood, 117(19), 5019-5032. https://doi.org/10.1182/blood-2011-01-293050

Chang, Y., Cui, M., Fu, X., Zhang, L., Li, X., Li, L., Wu, J., Sun, Z., Zhang, X., Li, Z., Nan, F., Yan, J., \& Zhang, M. (2019). MiRNA-155 regulates lymphangiogenesis in natural killer/T-cell lymphoma by targeting BRG1. Cancer Biology \& Therapy, 20(1), 31-41. https://doi.org/10.1080/ 15384047.2018.1504721 
Chen,Y. W., Guo, T., Shen, L.,Wong, K. Y., Tao Q., Choi, W. W., \& Srivastava, G. (2015). Receptor-type tyrosine-protein phosphatase kappa directly targets stat 3 activation for tumor suppression in nasal NK/T-cell lymphoma. Blood, 125, 1589-1600. https://doi.org/10.1182/ blood-2014-07-588970

Cohen, J. I., Iwatsuki, K., Ko, Y. H., Kimura, H., Manoli, I., Ohshima, K., Pittaluga, S., QuintanillaMartinez, L., \& Jaffe, E. S. (2020). Epstein-Barr virus NK and T cell lymphoproliferative disease: report of a 2018 international meeting. Leukemia \& Lymphoma, 61(4), 808-819. https://doi.org/10.1 080/10428194.2019.1699080

Coşkun, O., Yazici, E., Şahiner, F., Karakaş, A., Kiliç, S., Tekin, M., Artuk, C., Yammanel, L., \& Beşirbellioğlu, B. A. (2017). Cytomegalovirus and Epstein-Barr virus reactivation in the intensive care unit. Medizinische Klinik, Intensivmedizin und Notfallmedizin, 112(3), 239-245. https://doi.org/ 10.1007/s00063-016-0198-0

Crombie, J. L., \& LaCasce, A. S. (2019). Epstein Barr virus associated B-cell lymphomas and iatrogenic lymphoproliferative disorders. Frontiers in Oncology, 9, 109. https://doi.org/10.3389/ fonc. 2019.00109

de Arruda, J., Abrantes, T. C., Cunha, J., Roza, A., Agostini, M., Abrahão, A. C., Canedo, N., Ramos, D. D., Milito, C. B., Pontes, F., Pontes, H., Barra, M. B., Zanella, V. G., Martins, M., Martins, M. D., Israel, M. S., Freire, N. A., Barreto, M., Sánchez-Romero, C., Carlos, R., ... de Andrade, B. (2021). Mature T/NK-cell lymphomas of the oral and maxillofacial region: A multi-institutional collaborative study. Journal of Oral Pathology \& Medicine, 50(6), 548-557. https://doi.org/10.1111/jop.13205

de Mel, S., Hue, S. S.-S., Jeyasekharan, A. D., Chng, W.-J., \& Ng, S.-B. (2019). Molecular pathogenic pathways in extranodal NK/T cell lymphoma. Journal of Hematology \& Oncology, 12(1), 33. https://doi.org/10.1186/s13045-019-0716-7

de Mel, S., Soon, G. S.-T., Mok, Y., Chung, T.-H., Jeyasekharan, A. D., Chng, W.-J., \& Ng, S.-B. (2018). The genomics and molecular biology of natural killer/T-cell lymphoma: Opportunities for translation. International Journal of Molecular Science, 19, 1931. https://doi.org/10.3390/ ijms19071931

de Mel, S., Tan, J. Z.-C., Jeyasekharan, A. D., Chng, W.-J., \& Ng, S.-B. (2019). Transcriptomic abnormalities in Epstein Barr virus associated T/NK lymphoproliferative disorders. Frontiers in Pediatrics, 6, 355. https://doi.org/10.3389/ fped.2018.00405

Dobashi, A., Tsuyama, N., Asaka, R., Togashi, Y., Ueda, K., Sakata, S., Baba, S., Sakamoto, K., Hatake, K., \& Takeuchi K. (2016). Frequent BCOR aberrations in extranodal NK/T-cell lymphoma, nasal type. Genes Chromosomes Cancer, 55(5), 460-471. https://doi.org/10.1002/ gcc. 22348

Du, L., Zhang, L., Li, L., Li, X., Yan, J., Wang, X., Fu, X., Sun, Z., Zhang, X., Li, Z., Wu, J., Yu, H., Chang, Y., Zhou, Z., Nan, F., Wu, X., Tian, L., \& Zhang, M. (2020). Effective treatment with PD-1 antibody, chidamide, etoposide, and thalidomide (PCET) for relapsed/refractory natural killer/T-cell lymphoma: A report of three cases. OncoTargets and Therapy, 13, 7189-7197. https://doi.org/10.2147/OTT.S262039

Farrell, P. J. (2019) Epstein-Barr virus and cancer. Annual Review of Pathology, 24(14), 2953. https://doi.org/10.1146/annurev-path mechdis-012418-013023

Flavell, J. R., Baumforth, K. R. N., Wood, V. H. J., Davies, G. L., Wei, W., Reynolds, G., Morgan, S., Boyce, A., Kelly, G. L., Young, L., \& Murray, P. G. (2008). Down-regulation of the TGF-beta target gene, PTPRK, by the Epstein-Barr virusencoded EBNA1 contributes to the growth and survival of Hodgkin lymphoma cells. Blood, 111(1), 292-301. https://doi.org/10.1182/ blood-2006-11-059881

Fu, L., Gao, Z., Zhang, X., Tsang, Y. H., Goh, H. K., Geng, H., Shimizu, N., Tsuchivama, J., Srivastava, G., \& Tao, Q. (2009). Frequent concomitant epigenetic silencing of the stressresponsive tumor suppressor gene $C A D M 1$, and its interacting partner $D A L-1$ in nasal NK/T-cell lymphoma. International Journal of Cancer, 124, 1572-1578. https://doi.org/10.1002/ijc.24123 
Gao, F., He, S., \& Jin, A. (2020). MiRNAs and lncRNAs in NK cell biology and NK/T-cell lymphoma. Genes \& Diseases, 8(5), 590-602. https://doi.org/10.1016/j.gendis.2020.08.006

Goade, D. E., Nofchissey, R. A., Kusewitt, D. F., Hjelle, B., Kreisel, J., Moore, J., \& Lyons, C. R. (2001). Ultraviolet light induces reactivation in a murine model of cutaneous herpes simplex virus-1 infection. Photochemistry and Photobiology, 74(1), 108-114. https://doi.org/ 10.1562/0031-8655(2001)074<0108:uliria > 2.0.co;2

Griffin, B. D., Verweij, M. C., \& Wiertz, E. J. H. J. (2010). Herpesviruses and immunity: The art of evasion. Veterinary Microbiology, 16,143(1), 89100. https://doi.org/10.1016/j.vetmic.2010.02.017

Gruhne, B., Sompallae, R., \& Masucci. M, G. (2009) Three Epstein-Barr virus latency proteins independently promote genomic instability by inducing DNA damage, inhibiting DNA repair and inactivating cell cycle checkpoints. Oncogene, 28(45), 3997-4008. https://doi.org/ 10.1038/onc. 2009.258

Han, L., Liu, F., Li, R., Li, Z., Chen, X., Zhou, Z., Zhang, X., Hu, T., Zhang, Y., Young, K., Sun, S., Wen, J., \& Zhang, M. (2014). Role of programmed death ligands in effective T-cell interactions in extranodal natural killer/T-cell lymphoma. Oncology Letter, 8(4), 1461-1469. https://doi.org/ 10.3892/ol.2014.2356

Hansen, T. H., \& Bouvier, M. (2009). MHC class I antigen presentation: learning from viral evasion strategies. Nature Review Inmunology, 1, 9(7), 503-513.https://doi.org/10.1038/nri2575

Haverkos, B., M., Pan, Z., Gru, A., Freud, A., Rabinovitch, R., Welliver, M., Brad, O., Barrionuevo, C., Baiocchi, R. A., Rochford, R., \& Porcu, P. (2016). Extranodal NK/T cell lymphoma, nasal type (ENKTL-NT): An update on epidemiology, clinical presentation, and natural history in North American and European cases. Current Hematologic Malignancy Reports, 11(6), 514-527. https://doi.org/10.1007/s11899016-0355-9

Hialgrim, H., Friborg, J., \& Melbye, M. (2007). The epidemiology of EBV and its association with malignant disease. In: A. Arvin, et al., editors. Human Herpesviruses: Biology, Therapy, and Immunoprophylaxis (Chapter 53). Cambridge University.

Hislop, A. D., Ressing, M. E., van Leeuwen, D., Pudney V. A., Horst, D., Koppers-Lalic, D., Croft, N. P., Neefjes, J. J., Rickinson, A. B., \& Wiertz, E. J. H. J. (2007). A CD $8^{+}$T cell immune evasion protein specific to Epstein-Barr virus and its close relatives in Old World primates. Journal of Experimental Medicine, 204, 1863-1873. https://doi.org/10.1084/jem.20070256

Hong, H., Huang, H., Fang, X., Wang, Z., Ye, S., Zhang, H., Huang, Y., Guo, H., Chen, X., Liang, Ch., Pu, X., Cao, Y., Lin, S., Li, X., Ren, Q., Liu, Q., \& Lin, T. (2019). A prognostic index for nasaltype early-stage extranodal natural killer/Tcell lymphoma: A multicenter study. American Journal of Hematology, 94(5), E122-E124. https://doi.org/10.1002/ajh.25426

Horst, D., Van Leeuwen, D., Croft, N. P., Garstka, M. A., Hislop, A. D., Kremmer, E., Rickinson, A. B., Wiertz, E. J. H. J., \& Ressing, M. E. (2009). Specific targeting of the EBV lytic phase protein BNLF2a to the transporter associated with antigen processing results in impairment of HLA class I-restricted antigen presentation. Journal of Immunology, 182, 2313-2324. https://doi.org/ 10.4049/jimmunol.0803218

Horst, D., Burrows, S. R., Gatherer, D., van Wilgenburg, B., Bell, M. J., Boer, I. G., Ressing, M.E., \& Wiertz, E. J. (2012). Epstein-Barr virus isolates retain their capacity to evade $\mathrm{T}$ cell immunity through BNLF2a despite extensive sequence variation. Journal of Virology, 86(1), 572-577. https://doi.org/10.1128/JVI.05151-11

Huang, D., Song, T. L., Nairismägi, M. L., Laurensia, Y., Pang, W. L., Zhe, D., Wong, E., Wijaya, G. G., Tan, J., Tan, S. H., Lim, J. Q., Chia, B., Chan, J. Y., Tang, T., Somasundaram, N., Cheng, C. L., Politz, O., Liu, N., Lim, S. T., \& Ong, C. K. (2020). Evaluation of the PIK3 pathway in peripheral T-cell lymphoma and NK/T-cell lymphoma. British Journal of Haematology, 189(4), 731-744. https://doi.org/ 10.1111/bjh.16435 
Huang, L., Liu, D., Wang, N., Ling, S., Tang, Y., Wu, J., Hao, L., Luo, H., Hu, X., Sheng, L., Zhu, L., Wang, D., Luo, Y., Shang, Z., Xiao, M., Mao, X., Zhou, K., Cao, L., Dong, L., Zheng, X., Suio, P., ... Wang, Q. F. (2018). Integrated genomic analysis identifies deregulated JAK/ STAT-MYC-biosynthesis axis in aggressive NK-cell leukemia. Cell Research, 28(2), 172-186. https://doi.org/10.1038/cr.2017.146

Huang, Y., de Reynies, A., de Leval, L., Ghazi, B., Martin-Garcia, N., Travert, M., Bosq, J., Brière, J., Petit, B., Thomas, E., Coppo, P., Marafioti, T., Emile, J-F., Delfau-Larue, M-H., Schmitt, C., \& Gaulard, P. (2010). Gene expression profiling identifies emerging oncogenic pathways operating in extranodal NK/T-cell lymphoma, nasal type. Blood, 115, 1226-1237. https://doi.org/ 10.1182/blood-2009-05-221275

Hue, S. S., Oon, M. L., Wang, S., Tan, S. Y., \& Ng, S. B. (2020). Epstein-Barr virus-associated T- and NK-cell lymphoproliferative diseases: an update and diagnostic approach. Pathology, 52(1), 111-127. https://doi.org/10.1016/j.pathol.2019. 09.011

Hui, K. F., Yiu, S., Tam, K. P., \& Chiang, A. (2019). Viral-targeted strategies against EBV-associated lymphoproliferative diseases. Frontiers in Oncology, 9, 81. https://doi.org/10.3389/ fonc.2019.00081

Huynh. J., Chand, A., Gough, D., \& Ernst, M. (2019). Therapeutically exploiting STAT3 activity in cancer - using tissue repair as a road map. Nature Review Cancer, 19(2), 82-96. https://doi.org/ 10.1038/s41568-018-0090-8

Jo, J. C., Kim, M., Choi, Y., Kim, H-J., Kim, J. E., Wan, S., Kim, H., \& Cha, H. J. (2017). Expression of programmed cell death 1 and programmed cell death ligand 1 in extranodal NK/T-cell lymphoma, nasal type. Annals of Hematology, 96(1), 25-31. https://doi.org/10.1007/s00277-0162818-4

Kanno, H., Kojya, S., Li, T., Ohsawa, M., Nakatsuka, S., Miyaguchi, M., Harabuchi, Y., \& Aozasa, K. (2000). Low frequency of HLA-A*0201 allele in patients with Epstein-Barr viruspositive nasal lymphomas with polymorphic reticulosis morphology. International Journal of Cancer, 87(2), 195-199. https://doi.org/ 10.1002/1097-0215(20000715)87:2<195::AIDIJC6>3.0.CO;2-0

Kim, W. Y., Jung, H. Y., Nam, S. J., Kim, T. M., Heo, D. S., Kim, C. W., \& Jeon, Y. K. (2016). Expression of programmed cell death ligand 1 (PD-L1) in advanced stage EBV-associated extranodal $\mathrm{NK} / \mathrm{T}$ cell lymphoma is associated with better prognosis. Virchows Archives, 469(5), 581-590. https://doi.org/10.1007/s00428-016-2011-0

Kobayashi, H., Nagato, T., Takahara, M., Sato, K., Kimura, S., Aoki, N., Azumi, M., Tateno, M., Harabuchi, Y., \& Celis, E. (2008). Induction of EBV-latent membrane protein 1-specific MHC class II-restricted T-cell responses against natural killer lymphoma cells. Cancer Research, 68(3), 901-908. https://doi.org/10.1158/0008-5472. CAN-07-3212

Koo, G. C., Tan, S. Y., Tang, T., Poon, S. L., Allen, G. E., Tan, L., Chong, S.CH., Ong, W.S., Tay, K., Tao, M., Quek, R., Loong, S., Yeoh, K-W., Yap, S. P., Lee, K. A., Lim, L. C., Tan, D., Goh, Ch., Cutcutache, I., Yu, W., \& Lim, S. T. (2012). Janus kinase 3-activating mutations identified in natural killer/T cell lymphoma. Cancer Discovery, 2(7), 591-597. https://doi.org/10.1158/2159-8290. CD-12-0028

Kwong, Y.-L., Chan, T. S. Y., Tan, D., Kim, S. J., Poon, L.-M., Mow, B., Khong, P-L., Loong, F., Au-Yeung, R., Iqbal, J., Phipps, C., \& Tse, E. (2017). PD1 blockade with pembrolizumab is highly effective in relapsed or refractory NK/Tcell lymphoma failing l-asparaginase. Blood, 129(17), 2437-2442.https://doi.org/10.1182/ blood-2016-12-756841

Lanier, L. L. (2008). Evolutionary struggles between NK cells and viruses. Nature Review Immunology, 14, 8(4), 259-268. https://doi.org/10.1038/nri2276

Laurini, J. A., Perry, A. M., Boilesen, E., Diebold, J., MacLennan, K. A., Müller-Hermelink, H. K., Nathwani, B. N., Armitage, J. O., \& Weisenburge, D. D. (2012). Classification of non-Hodgkin lymphoma in Central and South America: a review of 1028 cases. Blood, 120(24), 4795-4801. https://doi.org/10.1182/blood-2012-07-440073

Lambris, J. D., Ricklin, D., \& Geisbrecht, B. V. (2008). Complement evasion by human pathogens. 
Nature Review Microbiology,1, 6(2),132-42. https://doi.org/10.1038/nrmicro1824

Lee, S., Park, H. Y., Kang, S. Y., Kim, S. J., Hwang, J., \& Lee, S., (2015). Genetic alterations of JAK/STAT cascade and histone modification in extranodal NK/T-cell lymphoma nasal type. Oncotarget, 6(19), 17764-17776. https://doi.org/ 10.18632/oncotarget.3776

Lehrich, B. M., Goshtasbi, K., Abiri, A., Yasaka, T. M., Papagiannopoulos, P., Tajudeen, B. A., Brem, E. A., \& Kuan, E. C. (2021). Treatment modalities and overall survival outcomes for sinonasal extranodal natural killer/T-cell lymphoma. Leukemia \& Lymphoma, 62(3), 727-730. https://doi.org/10.108 0/10428194.2020.1834097

Li, Z., Xia, Y., Feng, L. N., Chen, J. R., Li, H. M., Cui, J., Cai, Q. Q., Kim, K. S., Cai, Q-Q., Sim, K. S., Nairismagi, L., Laurensia, Y., Meah, W. Y., Liu, W-SH., Guo, Y-M, Chen, L-Z., Feng, Q-S., Pang, Ch. P., Chew, S. H., Chen, J., \& Bei, J. X. (2016). Genetic risk of extranodal natural killer T-cell lymphoma: a genome-wide association study. Lancet. Oncology, 17(9), 1240-1247. https://doi. org/10.1016/S1470-2045(16)30148-6.

Louten, J. (2016). Herpesviruses. Essential Human Virology, 235-256. Elsevier. https://doi.org/ 10.1016/B978-0-12-800947-5.00013-2

Lubinski, J., Nagashunmugam, T., \& Friedman, H. M. (1998). Viral interference with antibody and complement. Seminars in Cell \& Developmental Biology, 9(3), 329-337. https://doi.org/10.1006/ scdb.1998.0242

Lv, K., Li, X., Yu, H., Chen, X., Zhang, M., \& Wu, X. (2020). Selection of new immunotherapy targets for NK/T cell lymphoma. American Journal of Translational Research, 12(11), 7034-7047.

Ma, H., Shen, L., Yang, H., Gong, H., Du, X., \& Li, J. (2021). m6A methyltransferase Wilms' tumor 1 -associated protein facilitates cell proliferation and cisplatin resistance in NK/T cell lymphoma by regulating dual-specificity phosphatases 6 expression via m6A RNA methylation. IUBMB Life, 73(1), 108-117. https://doi.org/10.1002/ iub. 2410

Mainou, B. A., Everly, D. N., Jr, \& Raab-Traub, N. (2007). Unique signaling properties of CTAR1 in LMP1-mediated transformation. Journal of
Virology, 81(18), 9680-9692. https://doi.org/ 10.1128/JVI.01001-07

Mansfield, S., Dwivedi, V., Byrd, S., Trgovcich, J., Griessl, M., Gutknecht, M., \& Cook, C. H. (2016). Broncholaveolar lavage to detect cytomegalovirus infection, latency, and reactivation in immune competent hosts. Journal of Medical Virology, 88(8), 1408-1416. https://doi.org/ 10.1002/jmv.24472

Mao, Y., Wang, J., Zhang, M., Fan, W., Tang, Q., Xiong, S., Tang, X., Xu, J., Wang, L., Yang, Sh., Liu, S., Xu, L., Chen, Y., Xu, L., Yin, R., \& Zhu, J. (2017). A neutralized human LMP1-IgG inhibits ENKTL growth by suppressing the JAK3/ STAT3 signaling pathway. Oncotarget, 8(7), 10954-10965. https://doi.org/10.18632/oncotarget. 14032

Merlo, A., Turrini, R., Dolcetti, R., Martorelli, D., Muraro, E., Comoli, P., \& Rosato, A. (2010). The interplay between Epstein-Barr virus and the immune system: a rationale for adoptive cell therapy of EBV-related disorders. Haematologica, 95(10), 1769-1777. https://doi.org/10.3324/ haematol.2010.023689

Montes-Mojarro, I. A., Chen, B.-J., Ramirez-Ibarguen, A. F., Quezada-Fiallos, C. M., Pérez-Báez, W. B., Dueñas, D., Casavilca-Zambrano, S., OrtizMayor, M., Rojas-Bilbao, E., Garcia-Rivello, H., Metrebian, M.F., Narbaitz, M., Barrionuevo, C., Lome-Maldonado, C., Bonzheim, I., Fend, F., Steinhilber, J., \& Quintanilla-Martinez, L. (2020). Mutational profile and EBV strains of extranodal NK/T-cell lymphoma, nasal type in Latin America. Modern Pathology, 33(5), 781791. https://doi.org/10.1038/s41379-019-0415-5

Ng, S.-B., Selvarajan, V., Huang, G., Zhou, J., Feldman, A.L., Law, M., Kwong, Y-L., Shimizu, N., Kagami, Y., Aozasa, K., Salto-Tellez, M., \& Chng, W.-J. (2011). Activated oncogenic pathways and therapeutic targets in extranodal nasal-type NK/T cell lymphoma revealed by gene expression profiling. Journal of Pathology, 223, 496-510. https://doi.org/10.1002/path.2823

Ng, S. B., Chung, T. H., Kato, S., Nakamura, S., Takahashi, E., Ko, Y. H., Khoury, J. D., Yin, C. C., Soong, R., Jeyasekharan, A. D., Hoppe, M. M., Selvarajan, V., Tan, S. Y., Lim, S. T., 
Ong, C. K., Nairismägi, M. L., Maheshwari, P., Choo, S. N., Fan, S., Lee, C. K., ... Chng, W. J. (2018). Epstein-Barr virus-associated primary nodal T/NK-cell lymphoma shows a distinct molecular signature and copy number changes. Haematologica, 103(2), 278-287. https://doi.org/10.3324/haematol.2017.180430

Palser, A. L., Grayson, N. E., White, R. E., Corton, C., Correia, S., Ba Abdullah, M. M., Watson, S. J., Cotton, M., Arrand, J. R., Murray, P. G., Allday, M. J. Rickinson, A. B., Young, L. S., Farrell, P. J., \& Kellam, P. (2015). Genome diversity of Epstein-Barr virus from multiple tumor types and normal infection. Journal of Virology, 89(10), 5222-5237. https://doi.org/10.1128/JVI.03614-14

Peng, R. J., Han, B. W., Cai, Q. Q., Zuo, X. Y., Xia, T., Chen, J. R., Feng, L-N., Lim, J. Q., Chen, Sh-W., Zeng, M-Sh., Guo, Y-M., Li, B., Xia, X-J., Xia, Y., Laurensia, Y., Chia, B. K. H., Huang, H-Q, Young, K. H, Lim, S. T., Ong, Ch. K., \& Bei, J. X. (2019). Genomic and transcriptomic landscapes of Epstein-Barr virus in extranodal natural killer T-cell lymphoma. Leukemia, 33(6), 1451-1462. https://doi.org/10.1038/s41375-018-0324-5

Petrara, M., Freguja, R., Gianesin, K., Zanchetta, M. \& De Rossi, A. (2013). Epstein-Barr virusdriven lymphomagenesis in the context of human immunodeficiency virus type 1 infection. Frontiers in Microbiology, 4, 311. https://doi.org/ 10.3389/fmicb.2013.00311.

Polprasert, C., Takeuchi, Y., Makishima, H., Wudhikarn, K., Kakiuchi, N., Tangnuntachai, N., Assanasen, T., Sitthi, W., Muhamad, H., Lawasut, P., Kongkiatkamon, S., Bunworasate, U., Izutsu, K., Shiraishi, Y., Chiba, K., Tanaka, H., Miyano, S., Ogawa, S., Yoshida, K., \& Rojnuckarin, P. (2021). Frequent mutations in HLA and related genes in extranodal NK/T cell lymphomas. Leukemia \& Lymphoma, 62(1), 95-103. https://doi.org/10.1080 /10428194.2020.1821011

Pudney V. A., Leese A. M., Rickinson A. B., \& Hislop A. D. (2005). CD8+ immunodominance among Epstein-Barr virus lytic cycle antigens directly reflects the efficiency of antigen presentation in lytically infected cells. Journal Experimental Medicine, 201, 349-360. https://doi.org/10.1084/ jem.20041542
Quinn, L. L., Williams, L. R., White, C., Forrest, C., Zuo, J., \& Rowe, M. (2015). The missing link in Epstein-Barr virus immune evasion: the BDLF3 gene induces ubiquitination and downregulation of Major Histocompatibility Complex Class I (MHC-I) and MHC-II. Journal of Virology, 90(1), 356-367. https://doi.org/10.1128/JVI.02183-15

Ressing, M. E., van Gent, M., Gram, A. M., Hooykaas, M. J., Piersma, S. J., \& Wiertz, E. J. (2015). Immune evasion by Epstein-Barr virus. Current Topics in Microbiology and Immunology, 391, 355381. https://doi.org/10.1007/978-3-319-22834-1_12

Rickinson, A. B., \& Kieff, E. (2007). Epstein-Barr virus. In: D. M. Knipe, \& P. M. Howley, editors. Fields Virology (vol 2, 5th ed). Philadelphia: Lippincott Williams and Wilkins, 2655-2700

Rowe, M., \& Zuo, J. (2010). Immune responses to Epstein-Barr virus: molecular interactions in the virus evasion of CD8+ T cell immunity. Microbes and Infection, 12(3), 173-181. https://doi.org/ 10.1016/j.micinf.2009.12.001

Sánchez-Romero, C., Paes de Almeida, O., Rendón Henao, J., \& Carlos, R. (2019). Extranodal NK/ T-cell lymphoma, nasal type in Guatemala: An 86-case series emphasizing clinical presentation and microscopic characteristics. Head and Neck Pathology, 13(4), 624-634. https://doi. org/10.1007/s12105-019-01027-z

Sánchez-Romero, C., Bologna-Molina, R., Paes de Almeida, O., Santos-Silva, A. R., Prado-Ribeiro, A. C., Brandão, T. B., \& Carlos, R.. Extranodal NK/T cell lymphoma, nasal type: An updated overview. Critical Review in Oncology and Hematology, 2021 159:103237. https://doi.org/ 10.1016/j.critrevonc.2021.103237

Siouda, M., Frecha, C., Accardi, R., Yue, J., Cuenin, C., Gruffat, H., Manet, E., Herceg, Z., Sylla, B. S., \& Tommasino, M. (2014). Epstein-Barr virus down-regulates tumor suppressor DOK1 expression. PLoS Pathogens, 10(5), e1004125. https://doi.org/10.1371/journal.ppat.1004125

Somasundaram, N., Lim, J. Q., Ong, C. K., \& Lim, S. T. (2019). Pathogenesis and biomarkers of natural killer T cell lymphoma (NKTL). Journal of Hematology \& Oncology, 12(1), 28. https://doi.org/ 10.1186/s13045-019-0717-6 
Song, T. L., Nairismagi, M. L., Laurensia, Y., Lim, J. Q., Tan, J., Li, Z. M., Pang, W-L., Kizhakeyil, A., Wijaya, G-C., Huang, D-Ch., Nagarajan, S., Chia, B. K-H., Cheah, D., Liu, Y-H., Zhang, F., Rao, H-L., Tang, T., Wong, E. K-Y., Bei, J-X., Igbal, J., ...Ong, C. K. (2018). Oncogenic activation of the STAT3 pathway drives PD-L1 expression in natural killer/T-cell lymphoma. Blood, 132(11), 1146-1158. https://doi.org/10.1182/blood2018-01-829424

Stanfield, B. A., \& Luftig, M. A. (2017). Recent advances in understanding Epstein-Barr virus. F1000Research, 6, 386. https://doi.org/ 10.12688/f1000research.10591.1

Sun, L., Zhao, Y., Shi, H., Ma, C., \& Wei, L. (2015). LMP-1 induces surviving expression to inhibit cell apoptosis through the NF- $\mathrm{B}$ and PI3K/ Akt signaling pathways in nasal NK/T-cell lymphoma. Oncology Reports, 33, 2253-2260. https://doi.org/10.3892/or.2015.3847

Swerdlow, S., Campo, E., Pileri, S. A., Lee, N., Harald, S., Reiner, S., Advani, R., Ghielmini, M., Salles, G. A., Zelenetz, A. D., \& Jaffe, E. S. (2016). The 2016 revision of the World Health Organization classification of lymphoid neoplasms. Blood, 127(20), 2365-2390. https://doi.org/10.1182/ blood-2016-01-643569

Tsai, M. H., Lin, X., Shumilov, A., Bernhardt, K., Feederle, R., Poirey, R., Koop-Schneider, A., Pereira, B., Almeida, R., \& Delecluse, H. J. (2017). The biological properties of different EpsteinBarr virus strains explain their association with various types of cancers. Oncotarget, 8(6), 1023810254. https://doi.org/10.18632/oncotarget.14380

Tse, E., \& Kwong Y.- L. (2013). How I treat NK/Tcell lymphomas. Blood, 121(25), 4997-5005. https://doi.org/10.1182/blood-2013-01-453233

Wang, Z., Li, L., Su, X., Gao, Z., Srivastava, G. Murray, P. G., Ambinder, R., \& Tao, Q. (2012). Epigenetic silencing of the $3 \mathrm{p} 22$ tumor suppressor DLEC1 by promoter $\mathrm{CpG}$ methylation in non-Hodgkin and Hodgkin lymphomas. Journal Translation Medicine, 10, 209. https://doi.org 10.1186/14795876-10-209

Wiertz, E. J., Devlin, R., Collins, H. L., \& Ressing, M. E. (2007). Herpesvirus interference with major Histocompatibility Complex Class II-restricted
T-cell activation. Journal of Virology, 81(9), 4389-4396. https://doi.org/10.1128/JVI.01525-06

Walton, A. H., Muenzer, J. T., Rasche, D., Boomer, J. S., Sato, B., Brownstein, B. H., Pachot, A., Brrooks, T. L., Deych, E., Shannon, W. D., Green, J.M., Storch, A.G., \& Hotchkiss, R. S. (2014).

Reactivation of multiple viruses in patients with sepsis. PLoS One, 9(2), e98819. https://doi. org/10.1371/journal.pone.0098819

Xiong, J., Cui, B. W., Wang, N., Dai, Y. T., Zhang, H., Wang, C. F., Zhong, H. J., Cheng, S., Ou-Yang, B. S., Hu, Y., Zhang, X., Xu, B., Qian, W. B., Tao, R., Yan, F., Hu, J. D., Hou, M., Ma, X. J., Wang, X., Liu, Y. H., ... Zhao, W. L. (2020). Genomic and transcriptomic characterization of natural killer T cell lymphoma. Cancer Cell, 37(3), 403419.e6. https://doi.org/10.1016/j.ccell.2020.02.005

Yamaguchi, M., Suzuki, R., \& Oguchi, M. (2018). Advances in the treatment of extranodal NK/T-cell lymphoma, nasal type. Blood, 131(23), 2528-2540. https://doi.org/10.1182/ blood-2017-12-791418

Yamanaka, Y., Tagawa, H., Takahashi, N., Watanabe, A., Guo, Y.-M., Iwamoto, K., Yamashita, J., Saitoh, H., Kameoka, Y., Shimizu, N., Ichinohasama, R., \& Sawada, K.-I. (2009). Aberrant overexpression of microRNAs activates AKT signaling via down-regulation of tumor suppressors in natural killer-cell lymphoma/leukemia. Blood, 114(15), 3265-3275. https://doi.org/10.1182/ blood-2009-06-222794

Yan, J., Ng, S.-B., Tay, J. L., Lin, B., Koh T. L., Tan, J., Selvarajan, V., Liu, Sh-Ch., Bi, Ch., Wang, Sh., Choo, Sh-N., Shimizu, N., Huang, G., Yu, Q., \& Chng, W. (2013). EZH2 overexpression in natural killer/T-cell lymphoma confers growth advantage independently of histone methyltransferase activity. Blood, 121(22), 4512-4520. https://doi. org/10.1182/blood-2012-08-450494

Yang, Y., Wang, Y., Liu, X., He, X., Zhang, L. L., Wu, G., Qu, B. L., Qian, L. T., Hou, X. R., Zhang, F. Q., Qiao, X. Y., Wang, H., Li, G. F., Zhu, Y., Cao, J. Z., Wu, J. X., Wu, T., Zhu, S. Y., Shi, M., Xu, L. M., ... Li, Y. X. (2021). Progression-free survival at 24 months and subsequent survival of patients with extranodal NK/T-cell lymphoma: a China Lymphoma Collaborative Group (CLCG) 
study. Leukemia, 35(6), 1671-1682. https://doi.org/ 10.1038/s41375-020-01042-y

Ying, J., Li, H., Murray, P., Gao, Z., Chen, Y.-W., Wang, Y., Lee, K. Y., Chan, A. T. C., Ambinder, R. F., Srivastava, G., \& Tao, Q. (2007). Tumorspecific methylation of the 8p22 tumor suppressor gene DLC1 is an epigenetic biomarker for Hodgkin, nasal NK/T-Cell and other types of lymphomas, Epigenetics, 2(1), 15-21. https://doi.org/10.4161/epi.2.1.3883

Zuo, J., Currin, A., Griffin, B. D., Shannon-Lowe, C., Thomas, W. A., Ressing, M. E., Wiertz, E. J., \& Rowe, M. (2009). The Epstein-Barr virus G-protein- coupled receptor contributes to immune evasion by targeting MHC class I molecules for degradation. PLoS Pathology, 5, e1000255. https://doi.org/10.1371/journal.ppat.1000255

Zhou, J., Zhang, C., Sui, X., Cao, S., Tang, F., Sun, S., Wang, S., \& Chen, B. (2018). Histone deacetylase inhibitor chidamide induces growth inhibition and apoptosis in NK/T lymphoma cells through ATM-Chk2-p53-p21 signalling pathway. Investigational New Drugs, 36(4), 571-580. https://doi.org/10.1007/s10637-017-0552-y 